Article

\title{
Peri-Prostatic Adipocyte-Released TGF $\beta$ Enhances Prostate Cancer Cell Motility by Upregulation of Connective Tissue Growth Factor
}

\author{
Evelina La Civita ${ }^{1}$, Antonietta Liotti ${ }^{1}$, Michele Cennamo ${ }^{1}$, Felice Crocetto ${ }^{2} \mathbb{D}$, Matteo Ferro ${ }^{3} \mathbb{D}_{\text {, }}$ \\ Pasquale Liguoro $^{1}\left(\mathbb{D}\right.$, Amelia Cimmino ${ }^{4}$ (D), Ciro Imbimbo ${ }^{2}$, Francesco Beguinot ${ }^{1}$, Pietro Formisano ${ }^{1, * \mathbb{D}}$ \\ and Daniela Terracciano ${ }^{1, *(1)}$
}

1 Department of Translational Medical Sciences, University of Naples “Federico II”, 80131 Naples, Italy; eva.lacivita@gmail.com (E.L.C.); antonietta.liotti@unina.it (A.L.); michelecennamo1@gmail.com (M.C.); pasquale.liguoro@uslsudest.toscana.it (P.L.); beguino@unina.it (F.B.)

2 Department of Neurosciences, Sciences of Reproduction and Odontostomatology, University of Naples “Federico II", 80131 Naples, Italy; felice.crocetto@unina.it (F.C.); ciro.imbimbo@unina.it (C.I.)

3 Division of Urology, European Institute of Oncology, 20141 Milan, Italy; matteo.ferro@ieo.it

4 Institute of Genetics and Biophysic, National Research Council, 80131 Naples, Italy; amelia.cimmino@igb.cnr.it

* Correspondence: fpietro@unina.it (P.F.); daniela.terracciano@unina.it (D.T.)

\section{check for} updates

Citation: La Civita, E.; Liotti, A.; Cennamo, M.; Crocetto, F.; Ferro, M.; Liguoro, P.; Cimmino, A.; Imbimbo, C.; Beguinot, F.; Formisano, P.; et al. Peri-Prostatic Adipocyte-Released TGF $\beta$ Enhances Prostate Cancer Cell Motility by Upregulation of Connective Tissue Growth Factor. Biomedicines 2021, 9, 1692. https:// doi.org/10.3390/biomedicines9111692

Academic Editor: Massimo Moro

Received: 28 October 2021

Accepted: 12 November 2021

Published: 15 November 2021

Publisher's Note: MDPI stays neutral with regard to jurisdictional claims in published maps and institutional affiliations.

Copyright: (c) 2021 by the authors. Licensee MDPI, Basel, Switzerland. This article is an open access article distributed under the terms and conditions of the Creative Commons Attribution (CC BY) license (https:// creativecommons.org/licenses/by/ $4.0 /)$.
Abstract: Periprostatic adipose tissue (PPAT) has emerged as a key player in the prostate cancer (PCa) microenvironment. In this study, we evaluated the ability of PPAT to promote PCa cell migration, as well as the molecular mechanisms involved. Methods: We collected conditioned mediums from in vitro differentiated adipocytes isolated from PPAT taken from PCa patients during radical prostatectomy. Migration was studied by scratch assay. Results: Culture with CM of human PPAT (AdipoCM) promotes migration in two different human androgen-independent (AI) PCa cell lines (DU145 and PC3) and upregulated the expression of CTGF. SB431542, a well-known TGF $\beta$ receptor inhibitor, counteracts the increased migration observed in presence of AdipoCM and decreased CTGF expression, suggesting that a paracrine secretion of TGF $\beta$ by PPAT affects motility of PCa cells. Conclusions: Collectively, our study showed that factors secreted by PPAT enhanced migration through CTGF upregulation in AI PCa cell lines. These findings reveal the potential of novel therapeutic strategies targeting adipocyte-released factors and TGF $\beta$ /CTGF axis to fight advanced PCa dissemination.

Keywords: adipocytes; prostate cancer; TGF $\beta 1$; peri-prostatic adipose tissue; cell migration

\section{Introduction}

Prostate cancer $(\mathrm{PCa})$ is the most common tumor in male patients in Western countries [1]. Epidemiological data suggest a positive association between body mass index and advanced prostate cancer [2]. Excessive visceral adiposity corresponded to major probabilities of higher grade diagnosed PCa and poor clinical outcomes [3-7]. There is evidence that crosstalk with adipose tissue (AT) could affect PCa progression [8-11]. The prostate is encircled by periprostatic adipose tissue (PPAT). This fat layer is contiguous to the gland capsule [12], making it plausible that PPAT affects the prostate cancer malignant phenotype $[13,14]$. Accordingly, we recently demonstrated that a paracrine secretion of IGF-1 by PPAT reduced the docetaxel response of androgen-independent (AI) PCa cell lines [15]. Ribeiro et al. [14] showed that PPAT collected from obese patients was able to enhance migration of androgen-dependent (AD) and castration-resistant PCa cell lines.

Laurent et al. showed that PPAT stimulated extravasation of PCa cells by CCL7 release and extracapsular extension is a well-known predictor of PCa aggressiveness [16]. Accordingly, Sasaki et al. [17] demonstrated that the pre-therapy ratio between periprostatic 
and subcutaneous fat thickness can be useful as predictor of survival in men with advanced PCa treated with androgen deprivation therapy (ADT).

Thus, the molecular crosstalk between PPAT and PCa cells plays a crucial role in the prostate tumor microenvironment (TME) and might be the basis for more aggressive disease behavior.

In the present study we investigated the effects of adipocyte-released factors on $\mathrm{PCa}$ cell migration.

Clarifying the tumor-promoting factors secreted by PPAT and the underlying mechanisms of migration enhancement in PCa cells may allow the identification of prognostic biomarkers and therapeutic targets in patients with PCa.

\section{Materials and Methods}

\subsection{Materials}

Media, sera and antibiotics for cell culture were obtained from GIBCO (Thermo Fisher Scientific, Waltham, MA, USA). Antibodies against CTGF and glyceraldehyde-3-phosphate dehydrogenase (GAPDH) were obtained from Santa Cruz Biotechnology (Santa Cruz, CA, USA). Antibody against pSMAD2/3 (Ser 423/425) were obtained from Cell signaling Technology (Cell Signaling Technology, Danvers, MA, USA). Sodium dodecyl sulfatepolyacrylamide gel electrophoresis (SDS-PAGE) reagents were obtained from Bio-Rad (Hercules, CA, USA). All other chemicals were from Sigma-Aldrich (St Louis, MO, USA). Recombinant human TGF $\beta 1$ was purchased from R\&D (R\&D Systems Inc., Minneapolis, MN, USA), and SB431542 was purchased from MCE (MedChem Express, Monmouth Junction, NJ, USA).

\subsection{Cell Cultures}

LnCaP, DU145 and PC3 human prostate cancer cells were cultured in RPMI and DMEM, respectively, supplemented with $10 \%$ fetal bovine serum (FBS) and $2 \mathrm{mmol} / \mathrm{L}$ glutamine, $100 \mathrm{IU} / \mathrm{mL}$ penicillin and $100 \mathrm{IU} / \mathrm{mL}$ streptomycin. Cultures were maintained in a humidified atmosphere of $95 \%$ air and $5 \% \mathrm{CO}_{2}$ at $37^{\circ} \mathrm{C}$. Human periprostatic adipose tissue (PPAT) samples were obtained from 14 men who had undergone radical prostatectomy at the Division of Urology of the University Federico II (Naples, Italy) from September 2020 to January 2021. All men were free from metabolic or endocrine diseases. Informed written consent was obtained from every study participant before the surgical procedure. This procedure was approved by the ethical committee of the University of Naples "Federico II" (protocol number 118/20). Periprostatic adipose-derived Mesenchymal Stem Cells (Ad-MSCs) were isolated from the Stromal Vascular Fraction and differentiated in mature adipocytes as previously described [18].

\subsection{Conditioned Media System}

Mature adipocytes were washed two times with sterile phosphate-buffered saline (PBS) and incubated with serum-free media supplemented with $0.25 \%$ albumin bovine serum (BSA). After $24 \mathrm{~h}$, adipocyte-conditioned media (PPAT AdipoCM) were collected, centrifuged to remove cellular debris, and placed onto recipient cells.

\subsection{Scratch Assays}

LnCaP, DU145 and PC3 prostate cancer cell lines were seeded (5 $\times 10^{5}$ per well) in 12-well plates and allowed to adhere for $24 \mathrm{~h}$. Confluent monolayer cells were scratched by a $200 \mu \mathrm{L}$ pipette tip, washed three times with PBS to clear cell debris and suspension cells and a fresh medium was added. Cells were treated with the indicated stimuli and the cells were allowed to close the wound for $48 \mathrm{~h}$. Photographs were taken at 0 and $48 \mathrm{~h}$ at the same position of the wound and the distance between the edges was measured. 


\subsection{Cell Transfection}

DU145 and PC3 were transfected with Dicer-substrate RNAs (DsiRNAs, IDT Coralville, Coralville, IA, USA) by using Lipofectamine 3000 (Life Technologies, Carlsbad, CA, USA), in DMEM without antibiotics and serum, according to manufacturer's instructions. After $6 \mathrm{~h}$, the cells were feed with DMEM $10 \%$ FBS.

\subsection{Real-Time RT-PCR Analysis}

Total cellular RNA was isolated from DU145 and PC3 using QIazol reagent (QIAGEN Sciences, Hilden, Germany), according to manufacturer instructions. $1 \mu \mathrm{g}$ of cell RNA was reverse-transcribed using Superscript III Reverse Transcriptase (Life Technologies, Carlsbad, CA, USA). PCR reactions were analyzed using IQTM SYBR Green Supermix (Bio-Rad, Hercules, CA, USA). Reactions were performed using Platinum SYBR Green qPCR Super-UDG using an iCycler IQ multicolor Real Time PCR Detection System (Biorad, Hercules, CA, USA). All reactions were performed in triplicate and PPIA was used as an internal standard. Primer sequences: human CTGF F: 5' GGGAAATGCTGCGAGGAGT 3', R: 5' GATAGGCTTGGAGATTTTGG 3'; human PPIA F: 5' TACGGGTCCTGGCATCTTGT $3^{\prime}$, R: 5' GGTGATCTTCTTGCTGGTC $3^{\prime}$.

\subsection{Western Blot}

For Western blot assays, cells were washed with ice-cold phosphate-buffered saline (PBS) and harvested in a Laemmli buffer (with $\beta$-mercaptoethanol) containing a mixture of phosphatase inhibitors ( $0.5 \mathrm{mM}$ sodium vanadate, $2 \mathrm{mM}$ sodium pyrophosphate, $5 \mathrm{mM}$ $\beta$-glycerolphosphate, and $50 \mathrm{mM}$ sodium fluoride) and the protease inhibitor phenylmethylsulfonyl fluoride (Sigma-Aldrich). Western blots were carried out as previously reported [15].

\subsection{TGFß1 Elisa}

AdipoCM levels of human TGF $\beta 1$ were evaluated using ELISA assay (Invitrogen, Carlsbad, CA, USA) according to manufacturers' instructions.

\subsection{Statistical Analyses}

Statistical analyses were carried out using the GraphPad Prism software (version 9.0, C San Diego, CA, USA). Student's t-test was used to compare the means of two groups, while a one-way ANOVA test was used to compare the means of more than two groups. All data are presented as the mean \pm SD from at least three independent experiments. A two-sided $p$-value of less than 0.05 was considered statistically significant.

\section{Results}

3.1. PPAT Adipocyte-Conditioned Media-Induced Migration of Androgen-Independent PCa Cell Lines

PPAT samples were obtained from 14 men who underwent radical prostatectomy: 3 adenomas; 3 low-grade PCa [Gs $\leq 7(3+4)]$; and 7 high-grade PCa [Gs $\geq 7(4+3)]$.

To investigate whether PPAT AdipoCM can influence cell motility in Pca cells, a series of wound-healing scratch assays were conducted on three different cell lines (LnCaP, DU145 and PC3). PCa cells were serum-starved and then incubated with AdipoCM from PPAT. As shown in Figure 1, AdipoCM incubation significantly enhanced migration in DU145 and PC3 androgen-independent cell lines, but not in hormone sensitive cell line LnCaP. 


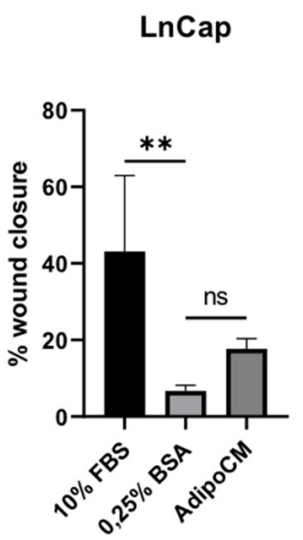

B

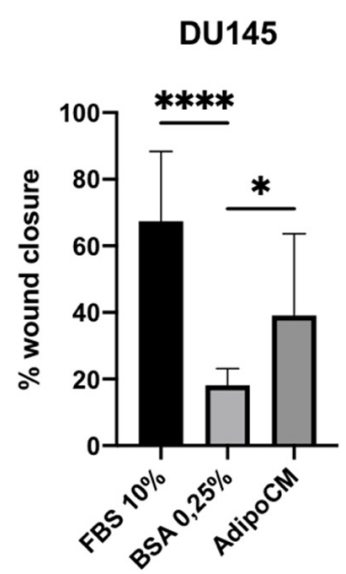

C

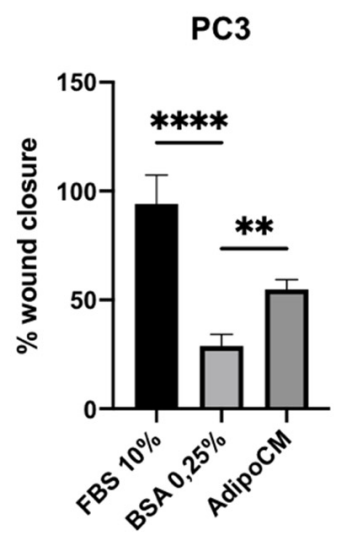

$10 \%$ FBS
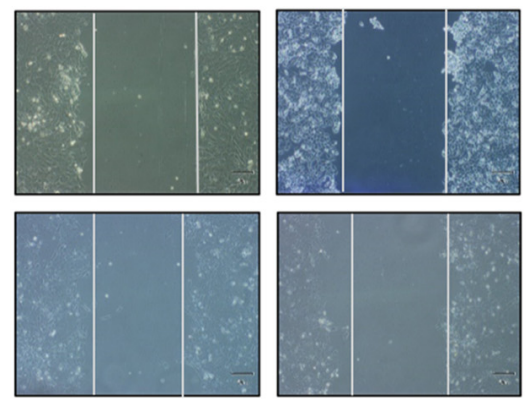

AdipoCM
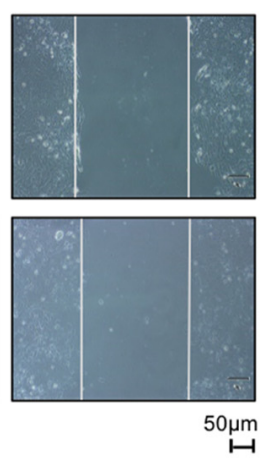

$\mathrm{T}=48 \mathrm{~h}$

$\mathrm{T}=\mathbf{0}$

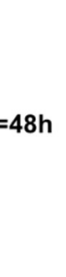

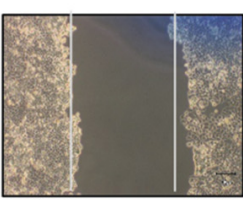

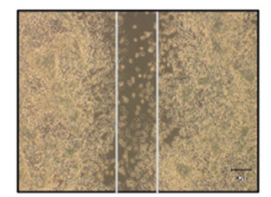

$10 \%$ FBS
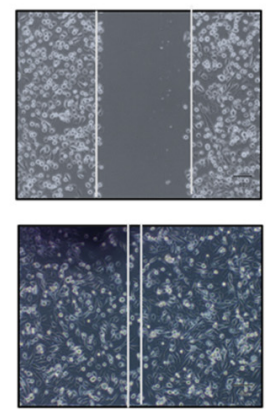

$0,25 \%$ BSA
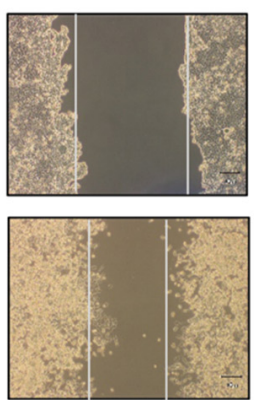

$0,25 \%$ BSA
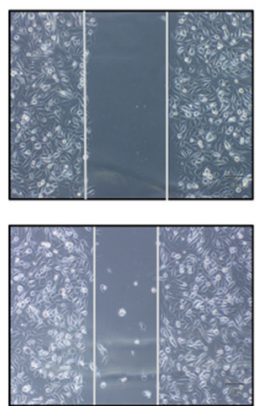

$\mathbf{T}=\mathbf{0}$

AdipoCM
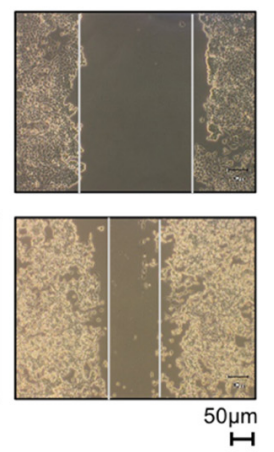

AdipoCM

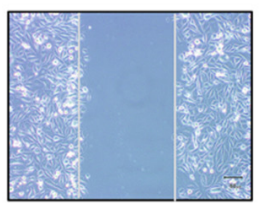

$\mathbf{T}=\mathbf{0}$

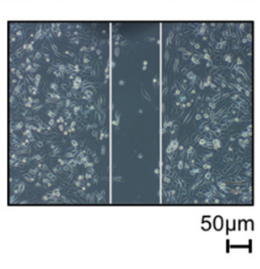

$\mathrm{T}=48 \mathrm{~h}$

Figure 1. Adipocyte-conditioned media-induced PCa cell lines migration. LnCaP (A), DU145; (B) and PC3; (C) cells were seeded $\left(5 \times 10^{5}\right.$ cells/well) in 12-well plates and allowed to form a confluent cell monolayer. Cell layers were wounded with a micropipette tip and then incubated with medium containing $10 \%$ FBS, $0.25 \%$ BSA or conditioned medium obtained from adipocytes. The images were acquired at 0 and $48 \mathrm{~h}$ using a camera connected to the microscope. Cell migration toward the wounded area was observed, photographed and measured (magnification $10 \times$ ). Graphs show the percentage of wound healing rate. ${ }^{*}$ Indicates a $p$-value $<0.05,{ }^{* *}$ indicates a $p$-value $<0.01$ and $* * * *$ a $p$-value $\leq 0.0001$. 


\subsection{PPAT Mature Adipocyte-Released TGFß1 Increased Cell Motility}

We speculated that TGF $\beta 1$ present in AdipoCM from PPAT could be the driver of increased migration capacity in DU145 and PC 3 cell lines. To test our hypothesis, we performed scratch assays using SB431542, a potent and selective TGF $\beta 1$ receptor inhibitor (Figure 2). Interestingly, TGF $\beta 1$ receptor inhibitor reduced AdipoCM capacity to induce PCa cell migration (Figure 2A,B). Then, we measured the concentration of TGF $\beta 1$ in AdipoCM. As shown in Table 1, we found that mature adipocytes secreted TGF $\beta 1$ at a medium concentration of $336,4 \pm 108,9 \mathrm{pg} / \mathrm{mL}$. Accordingly, we stimulated PCa cell lines with human recombinant TGF $\beta 1$ at a concentration of $400 \mathrm{pg} / \mathrm{mL}$, finding an effect comparable to AdipoCM. Our results suggest that TGF $\beta 1$ was the mediator of the motilitypromoting effect on the PCa cells of PPAT adipoCM.

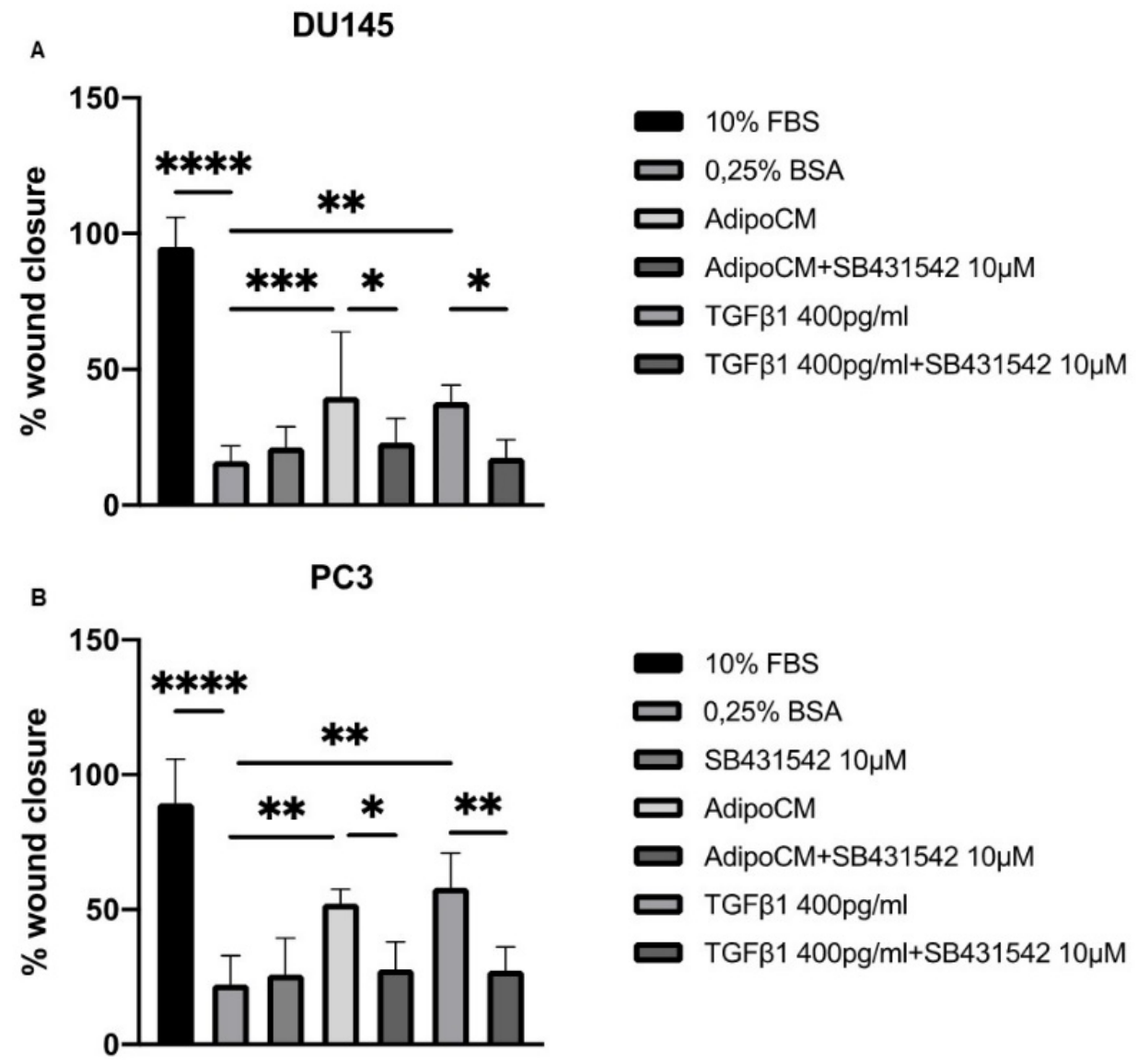

Figure 2. TGF $\beta 1$ receptor inhibitor counteracted the effect of AdipoCM on PCa cell lines migration. (A,B) DU145 and PC3 cells were seeded ( $5 \times 10^{5}$ cells/well) in 12-well plates and allowed to form a confluent cell monolayer. Cell layers were wounded with a micropipette tip and then incubated with medium containing $10 \%$ FBS, $0.25 \%$ BSA or conditioned medium obtained from adipocytes, human recombinant TGF $\beta 1(400 \mathrm{pg} / \mathrm{mL})$ and SB431542 $(10 \mu \mathrm{M})$ alone or in combination. The images were acquired at 0 and $48 \mathrm{~h}$ using a camera connected to the microscope. Cell migration toward the wounded area was observed, photographed and measured (magnification $10 \times$ ). Graphs show the percentage of wound healing rate. ${ }^{*}$ Indicates a $p$-value $<0.05,{ }^{* *}$ indicates a $p$-value $<0.01$, *** indicates a $p$-value $<0.001$ and ${ }^{* * * *}$ a $p$-value $\leq 0.0001$. 
Table 1. Clinicopathological characteristics of patients.

\begin{tabular}{|c|c|c|c|c|}
\hline \multicolumn{5}{|c|}{ Low Grade Patients } \\
\hline Patient Code & Age (Years) & BMI $\left(\mathrm{kg} / \mathrm{m}^{2}\right)$ & $\begin{array}{c}\text { Grading } \\
\text { (Gleason Score) }\end{array}$ & $\begin{array}{c}\text { Adipo-CM } \\
\text { TGF } \beta 1(\mathrm{pg} / \mathrm{mL})\end{array}$ \\
\hline 1 & 67 & 25 & $6(3+3)$ & 262.9 \\
\hline 2 & 66 & 31 & $7(3+4)$ & 303.4 \\
\hline 3 & 65 & 32 & $7(3+4)$ & 250.8 \\
\hline \multicolumn{5}{|c|}{ High grade patients } \\
\hline Patient Code & Age (years) & BMI $\left(\mathrm{kg} / \mathrm{m}^{2}\right)$ & $\begin{array}{c}\text { Grading } \\
\text { (Gleason Score) }\end{array}$ & $\begin{array}{c}\text { Adipo-CM } \\
\text { TGF } \beta 1(p g / m L)\end{array}$ \\
\hline 4 & 75 & 25 & $7(4+3)$ & 406.9 \\
\hline 5 & 77 & 23 & $8(4+4)$ & 396.9 \\
\hline 6 & 72 & 23 & $8(4+4)$ & 259.0 \\
\hline 7 & 77 & 26 & $8(4+4)$ & 376.2 \\
\hline 8 & 58 & 26 & $8(4+4)$ & 501.9 \\
\hline 9 & 69 & 24 & $8(4+4)$ & 382.6 \\
\hline 10 & 73 & 29 & $9(4+5)$ & 465.7 \\
\hline 11 & 74 & 28 & $9(4+5)$ & 478.0 \\
\hline \multicolumn{5}{|c|}{ BH patients (controls) } \\
\hline Patient code & Age (years) & BMI $\left(\mathrm{kg} / \mathrm{m}^{2}\right)$ & & $\begin{array}{c}\text { Adipo-CM } \\
\text { TGF } \beta 1(p g / m L)\end{array}$ \\
\hline 12 & 71 & 27 & - & 158.8 \\
\hline 13 & 66 & 37 & - & 284.1 \\
\hline 14 & 70 & 25 & - & 183.1 \\
\hline
\end{tabular}

\subsection{AdipoCM-Increased CTGF Expression}

Thereafter, we investigated the downstream signal transductors of adipocyte-released TGF $\beta 1$. We began to consider AdipoCM's ability to increase the expression of the connective tissue growth factor (CTGF). To investigate this, we incubated DU145 and PC3 cells with AdipoCM of four different patients, finding an increased CTGF protein expression (Figure 3). In addition, time course experiments showed that CTGF protein and mRNA expression was dynamically changed by AdipoCM incubation at different time points (Figure 3C,D), revealing a trend suitable for its involvement in migration.

A

\section{DU145}

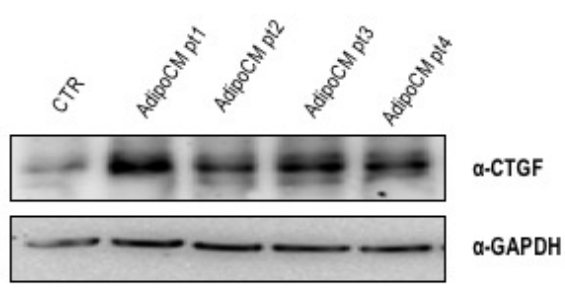

B

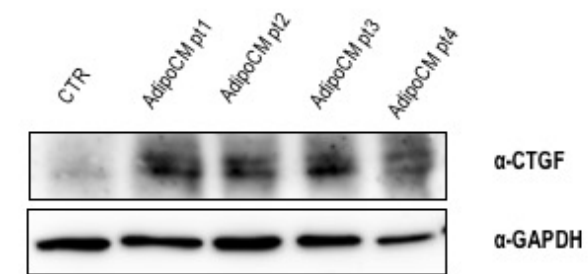

Figure 3. Cont. 
DU145

C

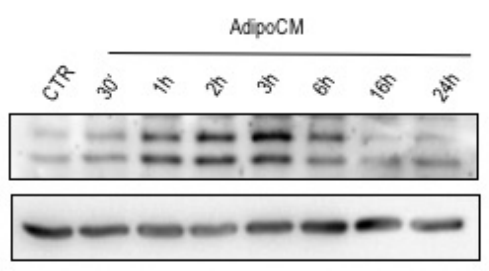

E

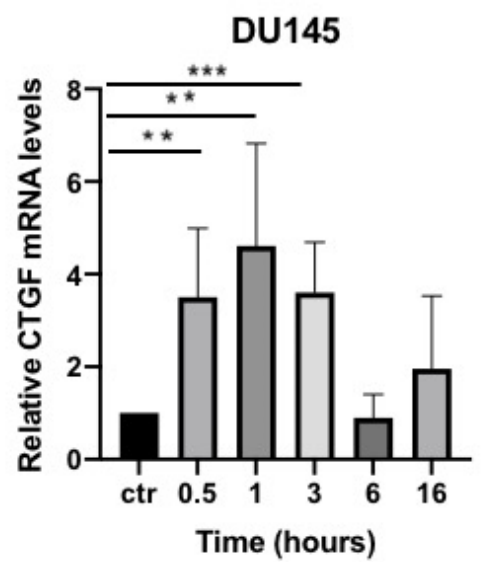

PC3

D

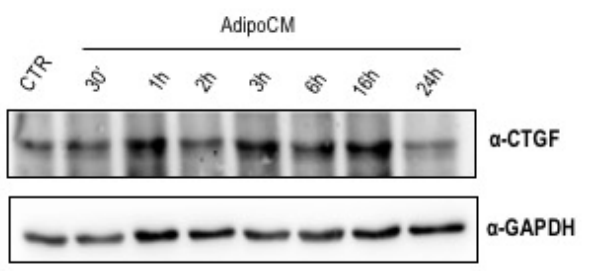

F

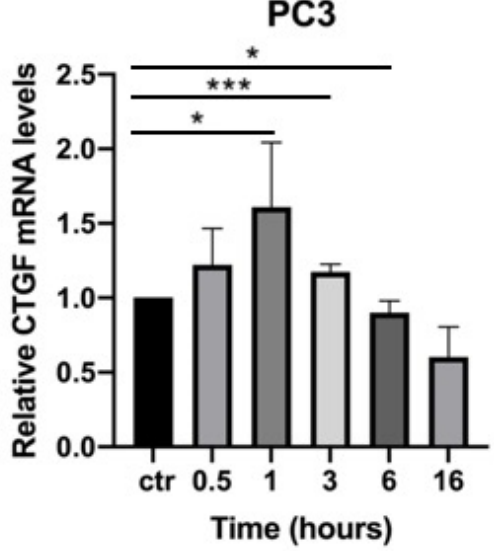

Figure 3. CTGF protein expression was upregulated by PPAT AdipoCM incubation. (A,B) DU145 and PC 3 cells were seeded $\left(2 \times 10^{5}\right.$ cells $/$ well $)$ in 12 -well plates and incubated with serum-free media or AdipoCM from five different PCa patients. Cells were solubilized, and protein samples analyzed by Western blot with CTGF antibody. GAPDH antibody was used for normalization. Blot results were revealed by ECL and the autoradiograph is representative of three independent experiments. (C,D) DU145 and PC3 cells were incubated with PPAT AdipoCM at different time points, as indicated. Protein expression of CTGF was analyzed by Western blot using GAPDH antibody for normalization. $(\mathrm{E}, \mathrm{F})$ mRNA abundance of CTGF was measured by real-time RT-PCR analysis of total RNA using PPIA as internal standard with CTGF antibody. GAPDH antibody was used for normalization. * Indicates a $p$-value $<0.05,{ }^{* *}$ indicates a $p$-value $<0.01$ and ${ }^{* * *}$ indicates a $p$-value $<0.001$.

\subsection{CTGF Was the Intracellular Transductor of Adipocyte-Released TGF $\beta 1$}

To test the hypothesis that CTGF could be the intracellular driver of adipocyte-released TGF $\beta 1$ 's effect on PCa migration, we evaluated its protein expression after SB431542 pretreatment, in DU145 and PC3 cells. As shown in Figure 4, the incubation with SB431542 reduced the increase of CTGF induced by AdipoCM as well as by human recombinant TGF $\beta 1400 \mathrm{pg} / \mathrm{mL}$.

The activation of TGF $\beta 1$ signaling was analyzed. Western blot analysis showed that AdipoCM incubation as well as human recombinant TGF $\beta 1$ increased phosphorylation of SMAD2/3. Accordingly, SMAD2/3 activation was decreased by SB431542 pretreatment (Figure $4 \mathrm{~A}, \mathrm{~B}$ ). 


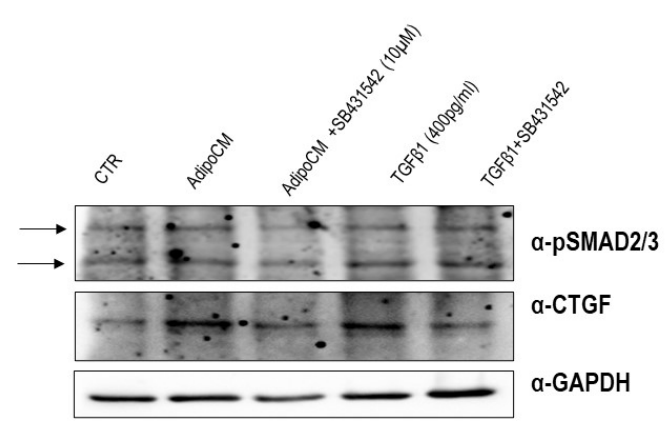

B

PC3

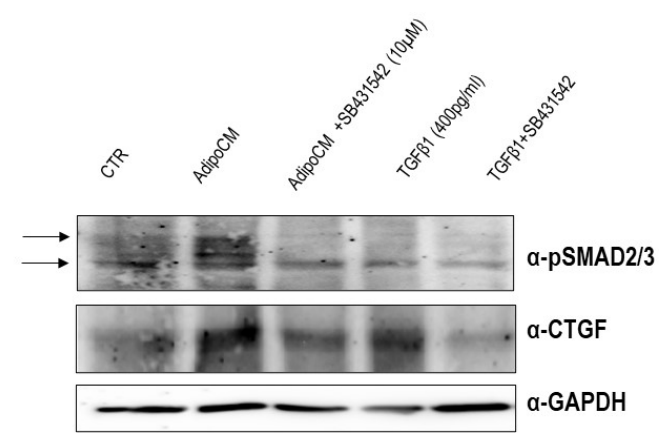

Figure 4. CTGF protein expression is reduced by TGF $\beta 1$ receptor inhibitor. (A,B) PCa cell lines were seeded $\left(2 \times 10^{5}\right.$ cells/well $)$ in multi-well plates and incubated with a medium containing $0.25 \%$ BSA or AdipoCM, human recombinant TGF $31(400 \mathrm{pg} / \mathrm{mL})$ and SB431542 $(10 \mu \mathrm{M})$ alone or in combination. Cells were solubilized and protein samples analyzed by Western blot with CTGF and pSMAD2/3 antibodies. GAPDH antibody was used for normalization. Blot results were revealed by ECL and autoradiograph.

To further verify our hypothesis, we performed scratch assays silencing CTGF. Firstly, we checked CTGF knockdown by Western blot (Figure S1), confirming that CTGF siRNA blocked its protein expression in both PCa cell lines. Secondly, we demonstrated that CTGF silencing significantly blocked the wound closure induced by AdipoCM in both PCa cell lines (Figure 5).

A

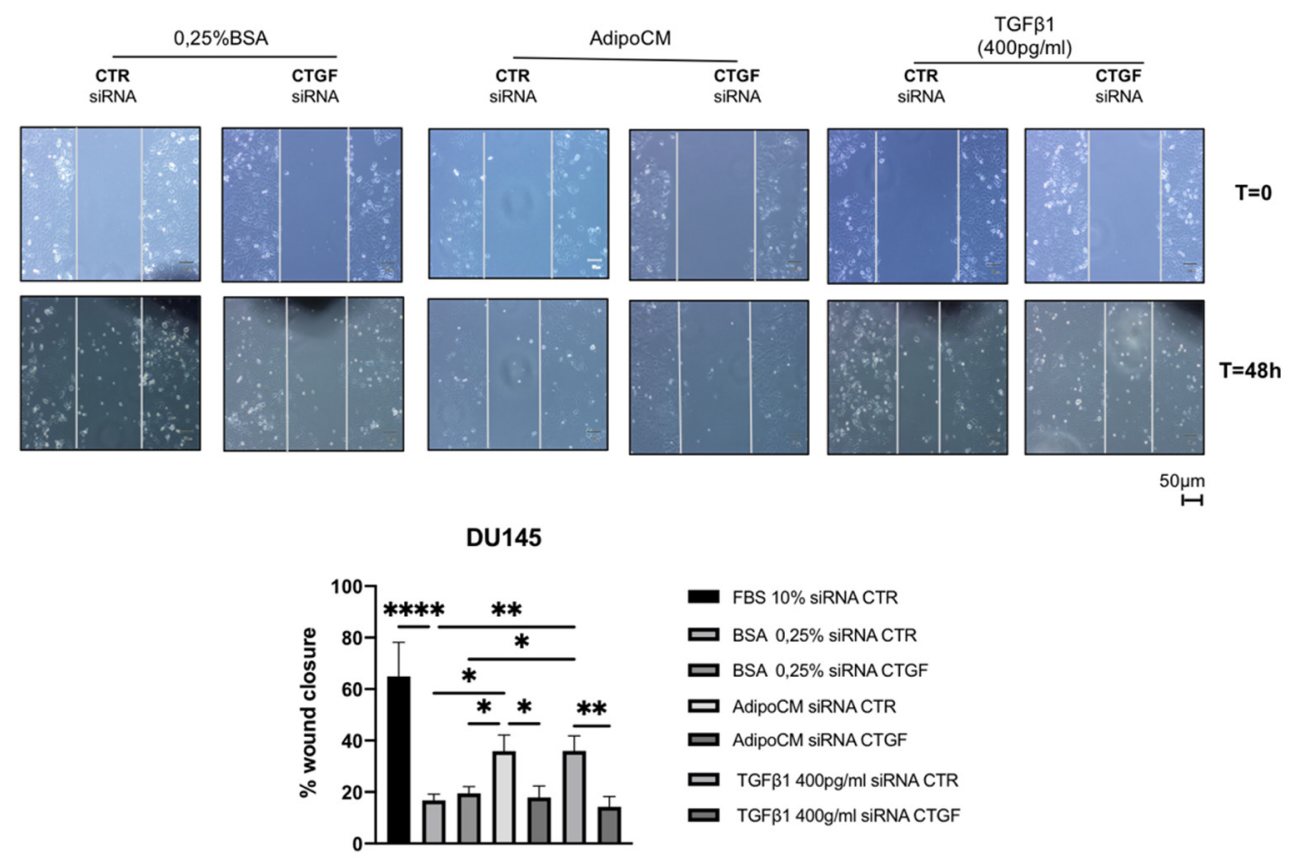

Figure 5. Cont. 
B

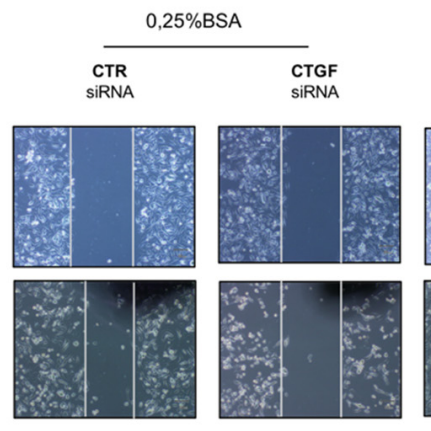

AdipoCM $\begin{array}{ll}\text { CTR } & \text { CTGF } \\ \text { SiRNA } & \text { SiRNA }\end{array}$
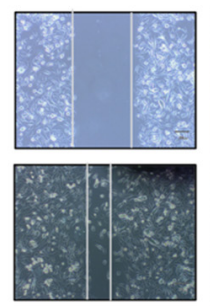
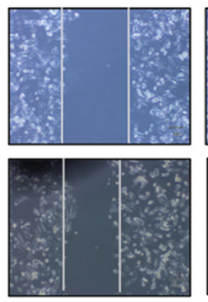

PC3

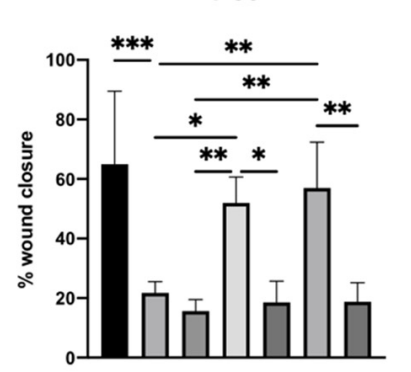

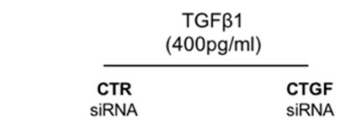
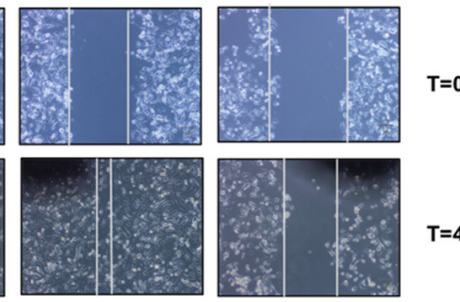

$\mathrm{T}=48 \mathrm{~h}$

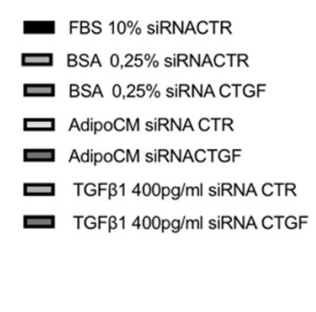

Figure 5. CTGF silencing counteracted the effect of AdipoCM on PCa cell migration. DU145 (A) and PC3 (B) cells were transfected with three different siRNAs recognizing CTGF (40 nM for DU145 and $10 \mathrm{nM}$ for PC3; siRNA CTGF) or with a control siRNA (40-10 nM; CTR siRNA). After $6 \mathrm{~h}$, the cells were fed with a complete medium. Then, the cells were allowed to form a confluent monolayer. Cell layers were wounded with a micropipette tip and then incubated with medium containing $0.25 \%$ BSA, conditioned medium obtained from adipocytes and TGF $\beta 1400 \mathrm{pg} / \mathrm{mL}$. The images were acquired at 0 and $48 \mathrm{~h}$ using a camera connected to the microscope. Cell migration toward the wounded area was observed, photographed and measured (magnification $10 \times$ ). Graphs show the percentage of wound healing rate. ${ }^{*}$ Indicates a $p$-value $<0.05,{ }^{* *}$ indicates a $p$-value $<0.01$, $* * *$ indicates a $p$-value $<0.001$ and ${ }^{* * * *}$ a $p$-value $\leq 0.0001$.

\section{Discussion}

The molecular mechanism linking PCa and AT is not completely clarified [19]. As there is a rising prevalence of obesity, understanding the underlying mechanisms of this biological connection is urgently needed. At present, obese and lean subjects receive the same treatment. However, obese patients had a poorer clinical outcome [20]. Thus, personalized therapeutic strategies based on patients' BMI or AT-associated measures may ameliorate their survival. To address this issue, it could be informative to investigate the effect of PPAT-released factors on the PCa cell aggressive phenotype. We previously demonstrated that adipose tissue-released IGF-1 contributed to docetaxel resistance of PCa cells [15]. In addition, the ability of adipocyte secretome to promote metastatic expansion has been clearly demonstrated in breast cancer [21]. There is growing evidence that adipocytes promote the malignant behavior of cancer cells [22]. Here, we show that AdipoCM from PPAT promotes migration in AI PCa cells through TGF- $\beta$ upregulation of CTGF (Figure 6). 


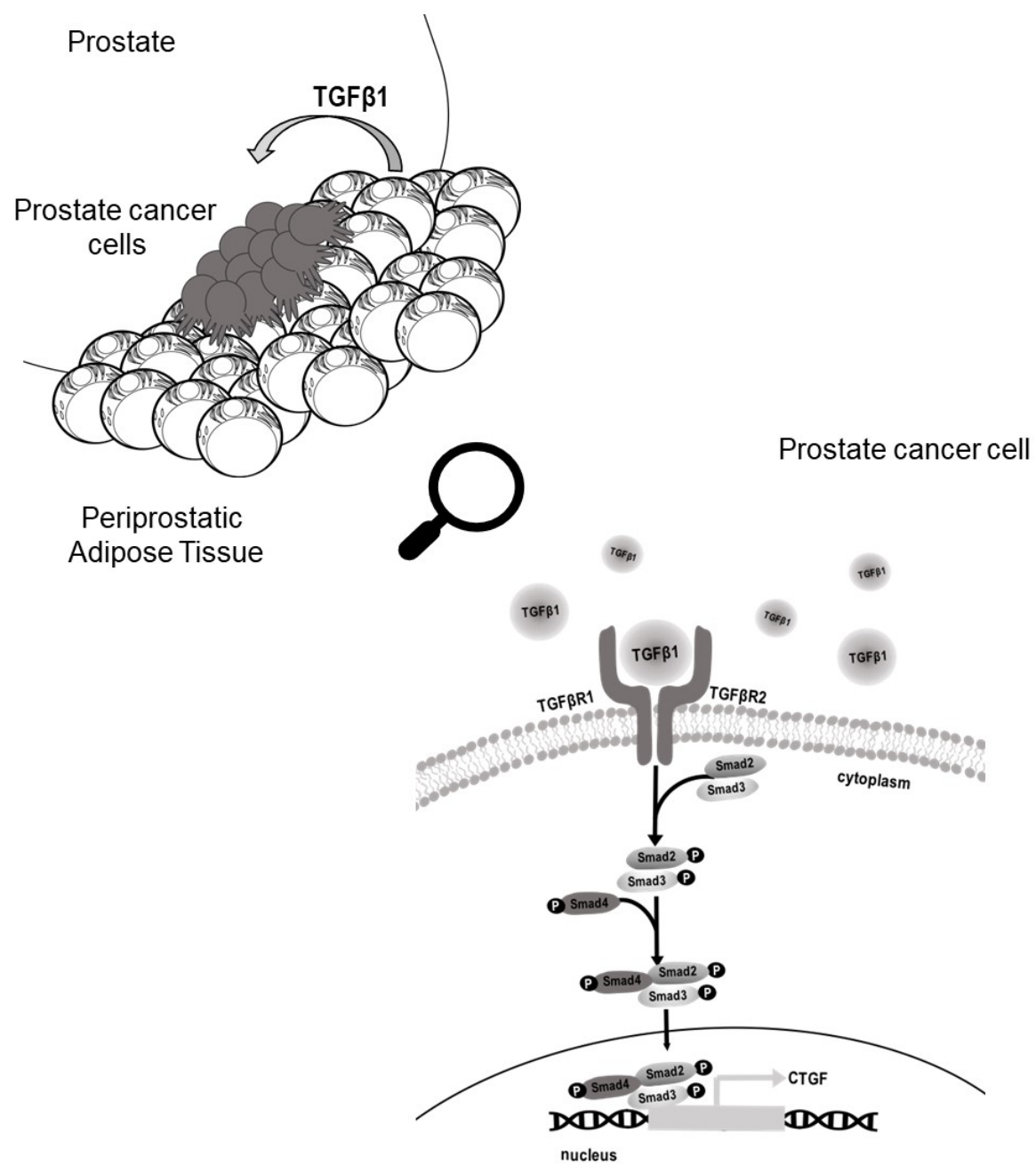

Figure 6. Schematic representation of the proposed role of PPAT in promoting migration in PCa cells. Periprostatic mature adipocytes released TGF $\beta 1$ upregulated CTGF expression in PCa cells favouring migration. CTGF, connective tissue growth factor; PCa, prostate cancer; PPAT, periprostatic adipose tissue; TGF $\beta$, tissue growth factor $\beta$.

This finding was consistent with previous research, since the role of TGF- $\beta$ in PCa is well-known and dual: it functions as anti-proliferative stimulus in the early stages, and then becomes a pro-metastatic factor in the advanced stage [23-26].

For this feature, TGF- $\beta$ was defined as the molecular "Jekyll and Hyde" of cancer [27] and, despite TGF $\beta$ signalling complexity in the tumor microenvironment, it can be targeted for therapeutic intervention.

Several studies showed that TGF- $\beta$ promoted migration of PCa cells, suggesting a strong association between TGF- $\beta$ signalling and PCa progression [28-31]. Ribeiro et al. [14] previously demonstrated that factors produced by AT explants significantly increased the migration of both hormone-refractory PC-3 and hormone-sensitive LNCaP cells. Contrarily to Ribeiro et al. [14], we used isolated adipocytes rather than whole ATs and we did not find effects on LNCaP cell migration. Our model allowed us to isolate the role of factors secreted from adipocytes, whereas the ex vivo method using explants revealed the effects of all the cellular components included in AT, including mature adipocytes, pre-adipocytes, fibroblasts and immune cells. It seems that adipocyte-released factors enhanced androgen-independent but not androgen-dependent motility. Conversely, whole adipose tissue secretion promoted the migration of both cells. It is plausible that the effect on androgen-sensitive cells is mediated by a different driver from TGF- $\beta$ and released by cellular components other than adipocytes. The lack of a migration-promoting 
effect of Adipo-CM on LNCaP was in agreement with the anti-oncogenic role played by TGF $\beta$ signalling in epithelial, but not in mesenchymal, cells [27]. Accordingly, higher expression of TGF- $\beta$ was reported in tumor tissues with higher Gleason score [32]. It is well accepted that TGF- $\beta$ affects the expression of several stromal derived factors involved in tumor progression, including CTGF through Smads $[33,34]$. Several authors reported that CTGF interacts with various integrins $(\alpha 2 \beta 1, \alpha 5 \beta 1, \alpha v \beta 6, \alpha v \beta 1)$ in normal cells [35-37]. In breast cancer cells, CTGF increased cell viability and migration via an integrin- $\alpha v \beta 3$ pathway $[38,39]$. Interestingly, upregulation of integrin- $\alpha \mathrm{v} \beta 3$ has been reported in bone metastatic cancer [40]. In addition, the role of CTGF in promoting the ability of breast and prostate cancer cells to establish bone metastasis has been recently demonstrated [41]. Moreover, protein interacting with PRKCA 1 (PICK1), a negative regulator of the TGF- $\beta$ pathway, can repress prostate cancer metastasis to bone [42]. In human PCa tissues, CTGF is upregulated in the advanced stage [43], highlighting the clinical relevance of our findings.

Here, we show, for the first time, that PCa cell migration was enhanced by CTGFincreased expression induced by adipocyte-released TGF- $\beta$, providing insights to the hypothesis that the TGF- $\beta$ /CTGF axis is a relevant mediator of the crosstalk between PCa and AT.

TGF- $\beta$ in PPAT may act in a paracrine manner, regulating function of the neighbor cells, including PCa cells. Accordingly, we showed that inhibition of the TGF- $\beta$ receptor by SB431542 decreased the effect of adipocyte-released factors on migration, thereby indicating that TGF- $\beta$ is a pivotal factor in the adipocyte regulation of PCa cell motility.

Our results are limited to an in vitro interaction model between PCa cells and adipocytes. Further studies are needed to assess the relevance of TGF- $\beta$ released by PPAT in the regulation of migration in PCa. However, our study strengthens the hypothesis that distinct AT (e.g., PPAT) may promote cancer dissemination [44] more than BMI. Accordingly, there is growing evidence that BMI did not mirror the role played by each type of AT [45]. Our findings reinforce the utility of the model measuring PPAT thickness rather than calculating the BMI to obtain clinically relevant information on PCa prognosis [17,44]. It could be valuable to combine PPAT-associated measures with PCa risk calculator to further improve PCa prognosis evaluation and to choose an individualized therapeutic strategy. Our results provided insight into molecular basis on the relationship between PPAT and PCa progression and envisioned the potential use of CTGF as a prognostic biomarker and the TGF- $\beta$ receptor as potential therapeutic target in patients with metastatic PCa. CTGF could be a reliable biomarker that will enable clinicians to choose the best therapeutic strategy for each individual PCa patient. Notably, there are several anti-cancer pharmacological agents that target the TGF- $\beta$ pathway that have already been tested in clinical trials for advanced PCa [46].

\section{Conclusions}

Increased migratory capacity is undoubtedly a hallmark of an unfavourable prognosis. Our results demonstrated for the first time in PCa that tumor-surrounding adipocytes promote migration through a CTGF-dependent mechanism, highlighting the relevant role played by PPAT on PCa clinical outcome and offering new chances to develop personalised treatment for patients with advanced PCa.

Supplementary Materials: The following are available online at https: / www.mdpi.com/article / 10.3390/biomedicines9111692/s1, Figure S1: Western blot analysis of CTGF silencing in DU145 and PC3 cells lines.

Author Contributions: Conceptualization, E.L.C. and D.T.; data curation, E.L.C., A.L., M.C., F.C. and P.L.; formal analysis, A.L. and E.L.C.; funding acquisition, P.F. and F.B.; investigation, E.L.C. and A.L.; methodology, D.T.; resources, F.C., C.I. and A.C.; supervision, P.F., F.B. and D.T.; validation, E.L.C., A.L.; visualization, D.T.; writing-original draft, E.L.C., A.L. and D.T.; writing-review \& editing, A.C., M.F. and D.T. All authors have read and agreed to the published version of the manuscript.

Funding: Supported by the "Finanziamento Ricerca di Ateneo 2020" (FRA 2020-Linea B) of the University of Naples Federico II. 
Institutional Review Board Statement: The study was conducted according to the guidelines of the Declaration of Helsinki, and approved by Ethics Committee of University of Naples "Federico II" (protocol code 118/20 of 7 May 2020).

Informed Consent Statement: Informed consent was obtained from all subjects involved in the study.

Data Availability Statement: The datasets used and/or analyzed during the current study are available from the corresponding author on reasonable request.

Acknowledgments: We would like to thank Domenico Liguoro for his valuable contributions to our research. We appreciate his technical support to our research-related activities.

Conflicts of Interest: The authors declare no conflict of interest.

\begin{abstract}
Abbreviations
PPAT: Peri-Prostatic Adipose Tissue; AdipoCM: Conditioned Medium of human PPAT; PCa: Prostate Cancer; CTGF: Connective-Tissue Growth Factor; AT: Adipose Tissue; BMI: Body Mass Index; TGF$\beta$ : Transforming Growth Factor- $\beta$; TME: Tumor Microenvironment; DMEM: Dulbecco's Modified Eagle Medium; FBS: Fetal Bovine Serum; AdMSCs: Adipocytes Mesenchymal Stem Cells; PBS: Phosphate-Buffered Saline; BSA: Bovine Serum Albumin; GAPDH: Glyceraldehyde-3-Phosphate Dehydrogenase; ELISA: Enzyme-Linked Immunosorbent Assays; TBS: Tris-Buffered Saline; mCRPC: Metastatic Castration-Resistant Prostate Cancer; EMT: Epithelial-Mesenchymal Transition; ADT: Androgen Deprivation Therapy; PPIA: Peptidylprolyl Isomerase A; SMAD2/3: Sma- And Mad-Related Proteins 2/3; AI: Androgen-Independent.
\end{abstract}

\title{
References
}

1. Siegel, R.L.; Miller, K.D.; Jemal, A. Cancer statistics, 2020. CA Cancer J. Clin. 2020, 70, 7-30. [CrossRef]

2. Harrison, S.; Tilling, K.; Turner, E.L.; Martin, R.M.; Lennon, R.; Lane, J.A.; Donovan, J.L.; Hamdy, F.C.; Neal, D.E.; Bosch, J.; et al. Systematic review and meta-analysis of the associations between body mass index, prostate cancer, advanced prostate cancer, and prostate-specific antigen. Cancer Causes Control 2020, 31, 431-449. [CrossRef] [PubMed]

3. De Nunzio, C.; Ficarra, V.; Tubaro, A.; Novara, G. Obesity and Prostate Cancer: The Tip of a High Mountain Still to Be Conquered. J. Clin. Med. 2020, 9, 2070. [CrossRef] [PubMed]

4. Dickerman, B.A.; Mucci, L.A. Obesity, height, and advanced prostate cancer: Extending current evidence toward precision prevention. Ann. Oncol. 2020, 31, 7-8. [CrossRef]

5. Mormile, R. Obesity at Diagnosis and Prostate Cancer Prognosis: A Challenge to Turn the Fate for the Better? Nutr. Cancer 2021, 73, 1079-1080. [CrossRef] [PubMed]

6. Tafuri, A.; Amigoni, N.; Rizzetto, R.; Sebben, M.; Shakir, A.; Gozzo, A.; Odorizzi, K.; De Michele, M.; Gallina, S.; Bianchi, A.; et al. Obesity strongly predicts clinically undetected multiple lymph node metastases in intermediate- and high-risk prostate cancer patients who underwent robot assisted radical prostatectomy and extended lymph node dissection. Int. Urol. Nephrol. 2020, 52, 2097-2105. [CrossRef]

7. Vidal, A.C.; Oyekunle, T.; Howard, L.E.; De Hoedt, A.M.; Kane, C.J.; Terris, M.K.; Cooperberg, M.R.; Amling, C.L.; Klaassen, Z.; Freedland, S.J.; et al. Obesity, race, and long-term prostate cancer outcomes. Cancer 2020, 126, 3733-3741. [CrossRef]

8. Finley, D.S.; Calvert, V.S.; Inokuchi, J.; Lau, A.; Narula, N.; Petricoin, E.F.; Zaldivar, F.; Santos, R.; Tyson, D.R.; Ornstein, D.K. Periprostatic adipose tissue as a modulator of prostate cancer aggressiveness. J. Urol. 2009, 182, 1621-1627. [CrossRef]

9. Stenman, U.H. Words of wisdom. Re: Periprostatic adipose tissue as a modulator of prostate cancer aggressiveness. Eur. Urol. 2010, 57, 541-542. [CrossRef]

10. Toren, P.; Venkateswaran, V. Periprostatic adipose tissue and prostate cancer progression: New insights into the tumor microenvironment. Clin. Genitourin. Cancer 2014, 12, 21-26. [CrossRef]

11. Venkatasubramanian, P.N.; Brendler, C.B.; Plunkett, B.A.; Crawford, S.E.; Fitchev, P.S.; Morgan, G.; Cornwell, M.L.; McGuire, M.S.; Wyrwicz, A.M.; Doll, J.A. Periprostatic adipose tissue from obese prostate cancer patients promotes tumor and endothelial cell proliferation: A functional and MR imaging pilot study. Prostate 2014, 74, 326-335. [CrossRef] [PubMed]

12. Ribeiro, R.J.; Monteiro, C.P.; Cunha, V.F.; Azevedo, A.S.; Oliveira, M.J.; Monteiro, R.; Fraga, A.M.; Principe, P.; Lobato, C.; Lobo, F.; et al. Tumor cell-educated periprostatic adipose tissue acquires an aggressive cancer-promoting secretory profile. Cell. Physiol. Biochem. 2012, 29, 233-240. [CrossRef] [PubMed]

13. Ribeiro, R.; Monteiro, C.; Catalan, V.; Hu, P.; Cunha, V.; Rodriguez, A.; Gomez-Ambrosi, J.; Fraga, A.; Principe, P.; Lobato, C.; et al. Obesity and prostate cancer: Gene expression signature of human periprostatic adipose tissue. BMC Med. 2012, 10, 108. [CrossRef] 
14. Ribeiro, R.; Monteiro, C.; Cunha, V.; Oliveira, M.J.; Freitas, M.; Fraga, A.; Principe, P.; Lobato, C.; Lobo, F.; Morais, A.; et al. Human periprostatic adipose tissue promotes prostate cancer aggressiveness in vitro. J. Exp. Clin. Cancer Res. 2012, 31, 32. [CrossRef] [PubMed]

15. Liotti, A.; La Civita, E.; Cennamo, M.; Crocetto, F.; Ferro, M.; Guadagno, E.; Insabato, L.; Imbimbo, C.; Palmieri, A.; Mirone, V.; et al. Periprostatic adipose tissue promotes prostate cancer resistance to docetaxel by paracrine IGF-1 upregulation of TUBB2B beta-tubulin isoform. Prostate 2021, 81, 407-417. [CrossRef]

16. Laurent, V.; Guerard, A.; Mazerolles, C.; Le Gonidec, S.; Toulet, A.; Nieto, L.; Zaidi, F.; Majed, B.; Garandeau, D.; Socrier, Y.; et al. Periprostatic adipocytes act as a driving force for prostate cancer progression in obesity. Nat. Commun. 2016, 7, 10230. [CrossRef] [PubMed]

17. Sasaki, T.; Sugino, Y.; Kato, M.; Nishikawa, K.; Kanda, H. Pre-treatment ratio of periprostatic to subcutaneous fat thickness on MRI is an independent survival predictor in hormone-naive men with advanced prostate cancer. Int. J. Clin. Oncol. 2020, 25, 370-376. [CrossRef]

18. D’Esposito, V.; Passaretti, F.; Hammarstedt, A.; Liguoro, D.; Terracciano, D.; Molea, G.; Canta, L.; Miele, C.; Smith, U.; Beguinot, F.; et al. Adipocyte-released insulin-like growth factor- 1 is regulated by glucose and fatty acids and controls breast cancer cell growth in vitro. Diabetologia 2012, 55, 2811-2822. [CrossRef]

19. Alvarez-Artime, A.; Garcia-Soler, B.; Sainz, R.M.; Mayo, J.C. Emerging Roles for Browning of White Adipose Tissue in Prostate Cancer Malignant Behaviour. Int. J. Mol. Sci. 2021, 22, 5560. [CrossRef]

20. Lopez, P.; Newton, R.U.; Taaffe, D.R.; Singh, F.; Buffart, L.M.; Spry, N.; Tang, C.; Saad, F.; Galvao, D.A. Associations of fat and muscle mass with overall survival in men with prostate cancer: A systematic review with meta-analysis. Prostate Cancer Prostatic Dis. 2021, 1-12. [CrossRef]

21. D’Esposito, V.; Ambrosio, M.R.; Giuliano, M.; Cabaro, S.; Miele, C.; Beguinot, F.; Formisano, P. Mammary Adipose Tissue Control of Breast Cancer Progression: Impact of Obesity and Diabetes. Front. Oncol. 2020, 10, 1554. [CrossRef]

22. Moraes, J.A.; Encarnacao, C.; Franco, V.A.; Xavier Botelho, L.G.; Rodrigues, G.P.; Ramos-Andrade, I.; Barja-Fidalgo, C.; RenovatoMartins, M. Adipose Tissue-Derived Extracellular Vesicles and the Tumor Microenvironment: Revisiting the Hallmarks of Cancer. Cancers 2021, 13, 3328. [CrossRef] [PubMed]

23. Ware, J.L. Growth factors and their receptors as determinants in the proliferation and metastasis of human prostate cancer. Cancer Metastasis Rev. 1993, 12, 287-301. [CrossRef] [PubMed]

24. Barrack, E.R. TGF beta in prostate cancer: A growth inhibitor that can enhance tumorigenicity. Prostate 1997, 31, 61-70. [CrossRef]

25. Lee, C.; Sintich, S.M.; Mathews, E.P.; Shah, A.H.; Kundu, S.D.; Perry, K.T.; Cho, J.S.; Ilio, K.Y.; Cronauer, M.V.; Janulis, L.; et al. Transforming growth factor-beta in benign and malignant prostate. Prostate 1999, 39, 285-290. [CrossRef]

26. Barron, D.A.; Rowley, D.R. The reactive stroma microenvironment and prostate cancer progression. Endocr. Relat. Cancer 2012, 19, R187-R204. [CrossRef] [PubMed]

27. Bierie, B.; Moses, H.L. Tumour microenvironment: TGFbeta: The molecular Jekyll and Hyde of cancer. Nat. Rev. Cancer 2006, 6 , 506-520. [CrossRef]

28. Nong, S.; Wang, Z.; Wei, Z.; Ma, L.; Guan, Y.; Ni, J. HN1L promotes stem cell-like properties by regulating TGF-beta signaling pathway through targeting FOXP2 in prostate cancer. Cell Biol. Int. 2021. [CrossRef]

29. Barrett, C.S.; Millena, A.C.; Khan, S.A. TGF-beta Effects on Prostate Cancer Cell Migration and Invasion Require FosB. Prostate 2017, 77, 72-81. [CrossRef]

30. Sun, D.Y.; Wu, J.Q.; He, Z.H.; He, M.F.; Sun, H.B. Cancer-associated fibroblast regulate proliferation and migration of prostate cancer cells through TGF-beta signaling pathway. Life Sci. 2019, 235, 116791. [CrossRef]

31. Vo, B.T.; Morton, D., Jr.; Komaragiri, S.; Millena, A.C.; Leath, C.; Khan, S.A. TGF-beta effects on prostate cancer cell migration and invasion are mediated by PGE2 through activation of PI3K/AKT/mTOR pathway. Endocrinology 2013, 154, 1768-1779. [CrossRef]

32. Reis, S.T.; Pontes-Junior, J.; Antunes, A.A.; Sousa-Canavez, J.M.; Abe, D.K.; Cruz, J.A.; Dall'oglio, M.F.; Crippa, A.; Passerotti, C.C.; Ribeiro-Filho, L.A.; et al. Tgf-beta1 expression as a biomarker of poor prognosis in prostate cancer. Clinics 2011, 66, 1143-1147. [CrossRef]

33. Strand, D.W.; Liang, Y.Y.; Yang, F.; Barron, D.A.; Ressler, S.J.; Schauer, I.G.; Feng, X.H.; Rowley, D.R. TGF-beta induction of FGF-2 expression in stromal cells requires integrated smad3 and MAPK pathways. Am. J. Clin. Exp. Urol. 2014, 2, $239-248$.

34. Hanna, A.; Humeres, C.; Frangogiannis, N.G. The role of Smad signaling cascades in cardiac fibrosis. Cell. Signal. 2021, 77, 109826. [CrossRef] [PubMed]

35. Hoshijima, M.; Hattori, T.; Inoue, M.; Araki, D.; Hanagata, H.; Miyauchi, A.; Takigawa, M. CT domain of CCN2/CTGF directly interacts with fibronectin and enhances cell adhesion of chondrocytes through integrin alpha5beta1. FEBS Lett. 2006, 580, 1376-1382. [CrossRef]

36. Hendesi, H.; Barbe, M.F.; Safadi, F.F.; Monroy, M.A.; Popoff, S.N. Integrin mediated adhesion of osteoblasts to connective tissue growth factor (CTGF/CCN2) induces cytoskeleton reorganization and cell differentiation. PLoS ONE 2015, 10, e0115325. [CrossRef] [PubMed]

37. Pi, L.; Robinson, P.M.; Jorgensen, M.; Oh, S.H.; Brown, A.R.; Weinreb, P.H.; Trinh, T.L.; Yianni, P.; Liu, C.; Leask, A.; et al. Connective tissue growth factor and integrin alphavbeta6: A new pair of regulators critical for ductular reaction and biliary fibrosis in mice. Hepatology 2015, 61, 678-691. [CrossRef] 
38. Chen, P.S.; Wang, M.Y.; Wu, S.N.; Su, J.L.; Hong, C.C.; Chuang, S.E.; Chen, M.W.; Hua, K.T.; Wu, Y.L.; Cha, S.T.; et al. CTGF enhances the motility of breast cancer cells via an integrin-alphavbeta3-ERK1/2-dependent S100A4-upregulated pathway. J. Cell Sci. 2007, 120, 2053-2065. [CrossRef]

39. Chien, W.; O’Kelly, J.; Lu, D.; Leiter, A.; Sohn, J.; Yin, D.; Karlan, B.; Vadgama, J.; Lyons, K.M.; Koeffler, H.P. Expression of connective tissue growth factor (CTGF/CCN2) in breast cancer cells is associated with increased migration and angiogenesis. Int. J. Oncol. 2011, 38, 1741-1747. [CrossRef] [PubMed]

40. Gupta, A.; Cao, W.; Chellaiah, M.A. Integrin alphavbeta3 and CD44 pathways in metastatic prostate cancer cells support osteoclastogenesis via a Runx2/Smad 5/receptor activator of NF-kappaB ligand signaling axis. Mol. Cancer 2012, 11, 66. [CrossRef]

41. Kim, B.; Kim, H.; Jung, S.; Moon, A.; Noh, D.Y.; Lee, Z.H.; Kim, H.J.; Kim, H.H. A CTGF-RUNX2-RANKL Axis in Breast and Prostate Cancer Cells Promotes Tumor Progression in Bone. J. Bone Miner. Res. 2020, 35, 155-166. [CrossRef]

42. Dai, Y.; Ren, D.; Yang, Q.; Cui, Y.; Guo, W.; Lai, Y.; Du, H.; Lin, C.; Li, J.; Song, L.; et al. The TGF-beta signalling negative regulator PICK1 represses prostate cancer metastasis to bone. Br. J. Cancer 2017, 117, 685-694. [CrossRef] [PubMed]

43. Gerashchenko, G.V.; Grygoruk, O.V.; Kononenko, O.A.; Gryzodub, O.P.; Stakhovsky, E.O.; Kashuba, V.I. Expression pattern of genes associated with tumor microenvironment in prostate cancer. Exp. Oncol. 2018, 40, 315-322. [CrossRef]

44. Dahran, N.; Szewczyk-Bieda, M.; Wei, C.; Vinnicombe, S.; Nabi, G. Normalized periprostatic fat MRI measurements can predict prostate cancer aggressiveness in men undergoing radical prostatectomy for clinically localised disease. Sci. Rep. 2017, 7, 4630. [CrossRef] [PubMed]

45. Donini, L.M.; Pinto, A.; Giusti, A.M.; Lenzi, A.; Poggiogalle, E. Obesity or BMI Paradox? Beneath the Tip of the Iceberg. Front. Nutr. 2020, 7, 53. [CrossRef]

46. Liu, S.; Ren, J.; Ten Dijke, P. Targeting TGFbeta signal transduction for cancer therapy. Signal Transduct. Target. Ther. $2021,6,8$. [CrossRef] [PubMed] 